\title{
Mobile Applications and Destination Branding in Spain
}

\author{
http://dx.doi.org/10.3991/ijim.v8i2.3575 \\ C.A. Scolari and J. Fernández-Cavia \\ Universitat Pompeu Fabra, Barcelona, Spain
}

\begin{abstract}
This article reports the findings of a study concerning mobile applications for tourism in 2013.

The research, which studied 66 applications, combined a quantitative description of this sector with qualitative categories based on a semiotic analysis. This article evaluates and compares the applications, identifies their main traits, and proposes a taxonomy which consists of: content-based applications, participatory applications and leisure applications.
\end{abstract}

Index Terms - Mobile media, mobile ecosystem, mobile applications, destination branding

\section{INTRODUCTION}

The tourism industry has traditionally been a sector in which the introduction of technology has taken place at a faster pace than in other fields [1]. Tourist destinations such as cities, regions or countries do not exist outside the developments of the digital world; they incorporate innovations in digital technology into their promotion strategies in an increasingly competitive environment [2]. Destination brands, like any other, present their offer, defend their position, and demonstrate their distinguishing traits to effectively reach their target audiences.

The organizations responsible for promoting tourism of a specific place, usually called Destination Marketing Organizations, or DMOs [3][4], have a wide range of tools at their disposal, ranging from traditional media such as television commercials, newspapers and magazine ads, brochures, fairs, etc. [5], to new digital interactive platforms such as websites, social networks and mobile communication [6][7][8][9][10][11].

Even if they should still be considered as media underconstruction, mobile devices occupy a central place in promoting tourism and communication strategies. Mobile marketing affords certain features that are especially appealing for the tourism industry such as ubiquitous access to information, customization, interactivity and, thanks to GPS technology, data segmented by geographical location [12]. Authors like Alqatan, Singh \& Ahmad [13] added size and ease-of-use to these features, especially if mobile devices are compared to traditional desktop and notebook computers.

\section{A. Recent research on mobile communication, tourism and branding}

Research situated at the crossroads of mobile communication, tourism and branding is highly novel and should be considered a work in progress. Instead, research on tourism, branding and digital communication holds a wellestablished place in media studies. Since its arrival in the early 90s, the World Wide Web has become a powerful platform for tourism communication and commerce. Media researchers did not take long to study these new ways of promoting a tourist destination. Considering that it is impossible to deal with production as a whole, in this section, we will merely indicate some recent and pertinent studies in this field.

User-generated content is one of the most important elements of any digital communication environment. Alacovska analyzed the complex interplay between audiences, labor relations, changing authorship patterns, technological shifts, and genre specificity in travel guide (book) publishing. Her research focused on the ways 'in which the publishing companies interpellate consumers (guidebook users) as producers and render what were previously irreplaceable experts (freelance travel writers) interchangeable' [14]. Researchers have also analyzed travel planning from these perspectives. Ayeh et al. [15] have observed that despite growing enthusiasm about social media, empirical research findings suggest that the majority of Internet users do not exploit user-generated content for travel planning.

The implementation and, consequently, the analysis of mobile strategies in the tourism industry are still insufficiently developed. According to Alqatan, Singh and Ahmad [13] little research has been conducted to explore the advantages of modern technologies like mobile commerce in the tourism industry in developing countries. Their proposal confirmed the importance of mobile commerce strategies in the tourism industry.

In a comparative study similar to our work, Jeffres \& Lin [16] developed an analysis of metropolitan websites. They examined how official websites of the core cities in the fifty largest metropolitan areas in the US (by population) portrayed their cities to the public as a whole, as well as how the cities communicated with their residents and visitors via these websites. Similarly, Bastida \& Huan [17] compared the tourism websites of Hong Kong, Shanghai, Beijing, and Taipei, analyzing website quality and usefulness. These authors found that the more appealing and useful an official destination website, the greater the likelihood of a potential tourist becoming an actual tourist.

Before the arrival of the new generation of smartphones (that is, before the release of the first iPhone in the summer of 2007) commercial applications in the field of mobile tourism basically fell within three main categories:

- Tourist or museum guides with pre-installed applications, namely rigidly defined content (in text, visual and auditory format) that cannot be customized according to user preferences; 
- Mobile devices used to access mobile web portals and browse tourist information of interest;

- Mobile electronic guide devices that use mobile network connections to access context-aware services.

The explosion of the application market introduced several changes in this ecosystem. Applications move in a different technological territory - they do not work on web standards like HTML language - and they must be downloaded from a specific platform (App Store, Google Play, etc.).

In an environment - the web - where content is likely to be free, the application market reintroduced payment for content as a business model. Applications are also very difficult to pirate and distribute on alternative channels. However, on many occasions, applications throw out the logic of the World Wide Web and afford a closed interactive interface, with no links to the rest of the net. In the specific field of tourism applications, in the space of a few years a whole new world of content and tools reached mobile devices (city maps, urban mobility, specific tourist guides, augmented reality systems, etc.).

In a recent article, Karanasios, Burgess \& Sellitto [18] propose a classification and a framework for evaluating mobile tourism applications. They divide tourism applications into two major groups: destination guides and travel tools, although some overlapping may occur. In order to analyze them, these authors develop a categorization based on four general dimensions: service delivery (information, transaction or community), customization (context or adaptation), initiation (push or pull) and application type (pre-installed-live, pre-installed-static or web based).

\section{B. Understanding mobile communication of tourist destinations in Spain}

A research published in 2010 - Observatorio sobre Tendencias en Internet de los Viajeros en España (http://www.minube.com/observatorio) - found that over $80 \%$ of Spanish mobile users made travel-related queries using their devices, and that $30 \%$ of them downloaded tourism applications. However, the use of mobile media by Spanish tourist destinations is still in an early stage of development [19]. More than half of Spanish cities, provinces and autonomous communities lack tourism mobile applications, whether developed by the official tourism institution, third parties or assumed as part of the official communication strategy. This general situation, as shown on the following pages, has already changed; applications are increasing their presence in Spanish tourist destination communication strategies.

This article sets out a mere fraction of a broader research initiative on online communication and destination branding in Spain. The overall objective of the research is to evaluate the adequacy and consistency of online communication of tourist destinations in Spain. The research includes:

- The analysis of the communication strategies of tourist destinations and how they make use of new technologies.

- The evaluation of official tourism websites including more than ten indicators: usability, quality and quantity of information, treatment of the brand image, discourse analysis, marketing, social web, interactivity, etc.
- The development of an original methodology for evaluating destination communication through social networks.

- The study of mobile applications recommended by official or tourist destinations. This article focuses on this fraction of the research.

It is widely known that the application ecosystem is a complex, dynamic and heterogeneous environment that changes every second. Thousands of devices, applications, technologies, individual players (designers, developers, marketers, etc.) and institutions (companies, public organizations, etc.) are frenetically interacting in real time and transforming the configuration of the whole system. In this context, this article should be considered a snapshot of a complex system characterized by continuous mutations and changes.

\section{METHODOLOGY}

The analysis of the applications was carried out between February 11 and March 9, 2013, and included 72 mobile applications, whether official or recommended through the official destination website.

The applications were analyzed using different mobile devices: iPhone 3GS (iOS 6.0), Samsung Galaxy Ace (Android 2.3 Gingerbread) and Sony Xperia T (Android 4.0 Ice Cream Sandwich). After a series of technical problems (five applications failed to work properly after being downloaded and another one was the same application for the city and the province) the original list was reduced to 66 applications.

To facilitate the analysis, the applications were identified according to the Spanish political organization of the territory in the cities, provinces and autonomous communities (regions). In Spain there are 17 autonomous communities and 2 autonomous cities (Ceuta and Melilla); these communities are divided into 50 provinces. Each province has a political capital (i.e., Galicia > Santiago de Compostela). Most of the provinces are named after their main city (Barcelona $>$ Barcelona, Girona $>$ Girona, etc.). The origin of the applications was the following:

TABLE I.

ORIGIN OF THE APPLICATION

\begin{tabular}{|l|c|l|}
\hline \multicolumn{1}{|c|}{ Categories } & Applications & \multicolumn{1}{c|}{ Examples } \\
\hline Auton. Comm. & 19 & Catalonia, Galicia, etc. \\
\hline Provinces & 15 & Murcia, Segovia, etc. \\
\hline Cities & 32 & Barcelona, Malaga, etc. \\
\hline Total & $\mathbf{6 6}$ & \\
\hline
\end{tabular}

For the analysis of the applications the research team developed a model based on previous mobile communication [19][20][21] and website research [22] [23][24][25]. The model is founded on the identification of a series of manifest features in the applications (i.e., business model, number of languages, functions, identification, presence of social networks, etc.). This first approach to the universe of Spanish tourism applications was complemented by an analysis that included semiotic categories like model user. 
Each one of the features and categories applied for the analysis will be explained in the following sections.

\section{GENERAL DESCRIPTION OF THE APPLICATIONS}

This section introduces the general properties of the Spanish tourism mobile applications. At the same time, it anticipates some emerging traits and questions derived from them.

\section{A. Business model and production}

From the perspective of the business model, most of the applications $(89.5 \%)$ were free:

TABLE II.

BUSINESS MODEL

\begin{tabular}{|l|c|c|c|c|}
\hline \multicolumn{1}{|c|}{ Categories } & Free & Pay & Freemium & Total \\
\hline Auton. Comm. & 18 & - & 1 & 19 \\
\hline Provinces & 14 & - & 4 & 18 \\
\hline Cities & 27 & 1 & 1 & 29 \\
\hline Total & $\mathbf{5 9}$ & $\mathbf{1}$ & $\mathbf{6}$ & $\mathbf{6 6}$ \\
& $\mathbf{( 8 9 . 5 \% )}$ & $(\mathbf{1 . 5 \% )}$ & $\mathbf{( 9 \% )}$ & $\mathbf{( 1 0 0 \% )}$ \\
\hline
\end{tabular}

The applications released under the freemium model were provided for free, but money was charged for advanced features and extra content. Among these features and content we can indicate the following: special routes (i.e., La Rioja, Barcelona), audio guides (i.e., Santiago de Compostela) or old pictures (i.e., BCN Visual). The only paid application was created by Barcelona and it specialized in one single cultural subject: Gaudi $B C N(€ 1.79)$.

Regarding the producer, in most cases $(63.6 \%)$ the applications were produced by external technological companies:

TABLE III.

INTERNAL-EXTERNAL PRODUCTION

\begin{tabular}{|l|c|c|c|}
\hline \multicolumn{1}{|c|}{ Categories } & Internal & External & Total \\
\hline Auton. Comm. & 5 & 14 & 19 \\
\hline Provinces & 7 & 8 & 15 \\
\hline Cities & 12 & 20 & 32 \\
\hline Total & $\mathbf{2 4 ( 3 6 . 5 \% )}$ & $\mathbf{4 2}(\mathbf{6 3 . 5 \% )}$ & $\mathbf{6 6}(\mathbf{1 0 0 \% )}$ \\
\hline
\end{tabular}

In any case, the relationships between the applications, public tourism agencies and the producers are complex and may adopt different types. During the research three situations were identified:

- Unofficial applications produced by external companies and recommended by public agencies (21\%).

- Unofficial applications produced by individuals and recommended by public agencies $(3 \%)$.

- Official applications produced or commissioned by public agencies. The latter model was the one most adopted by the Destination Marketing Organizations $(76 \%)$.

TABLE IV.

OFFICIAL-UNOFFICIAL PRODUCTION

\begin{tabular}{|l|c|c|c|c|}
\hline \multicolumn{1}{|c|}{ Categories } & $\begin{array}{c}\text { Unofficial } \\
\text { (company) }\end{array}$ & $\begin{array}{c}\text { Unofficial } \\
\text { (individual) }\end{array}$ & Official & Total \\
\hline Auton.Comm. & 8 & 1 & 10 & 19 \\
\hline Provinces & 2 & 0 & 13 & 15 \\
\hline Cities & 4 & 1 & 27 & 32 \\
\hline Total & $\mathbf{1 4}$ & $\begin{array}{c}\mathbf{2} \\
(\mathbf{3} \%)\end{array}$ & $\begin{array}{c}\mathbf{5 0} \\
\mathbf{( 7 6 \% )}\end{array}$ & $\begin{array}{c}\mathbf{6 6} \\
(\mathbf{1 0 0} \%)\end{array}$ \\
\hline
\end{tabular}

\section{B. Languages}

Language is a key issue in tourism applications: the translation of content into other languages gives the researcher information about the official tourism policy and, from a theoretical perspective, it serves to identify the model user [22]. In other words: Who is the application talking to? Most of the applications analyzed during the research $(60 \%)$ were developed in only one language (usually Spanish). This is not good news for the internationalization of the Spanish tourism industry.

TABLE V.

LANGUAGES

\begin{tabular}{|l|c|c|c|c|c|}
\hline \multicolumn{1}{|c|}{ Categories } & $\mathbf{1}$ & $\mathbf{2}$ & $\mathbf{3}$ & $\mathbf{4}$ or + & Total \\
\hline Auton.Comm. & 13 & 3 & 1 & 2 & 19 \\
\hline Provinces & 12 & 2 & 0 & 1 & 15 \\
\hline Cities & 15 & 4 & 8 & 5 & 32 \\
\hline Total & $\begin{array}{c}\mathbf{4 0} \\
\mathbf{( 6 0 \% )}\end{array}$ & $\begin{array}{c}\mathbf{9} \\
(\mathbf{1 4 \%})\end{array}$ & $\begin{array}{c}\mathbf{9} \\
\mathbf{( 1 4 \% )}\end{array}$ & $\begin{array}{c}\mathbf{8} \\
(\mathbf{1 2 \%})\end{array}$ & $\begin{array}{c}\mathbf{6 6} \\
(\mathbf{1 0 0 \% )}\end{array}$ \\
\hline
\end{tabular}

Regarding the translation of the texts into other languages, 5 applications only translated part of them while 21 translated all content.

\section{Hypertextual connections}

How do users reach the application? Are there any hypertextual links between the official tourism webpage and the application download page? Our research discovered that only $56 \%$ of the applications (37) were connected to the official websites. As consistency and logical articulation of communication in different media and platforms is a key issue of any strategy, the disconnect detected in this study should be further analyzed in future research: Are mobile communication strategies independent from web strategies? Are different teams working on the interactive communication of tourist destinations?

TABLE VI.

WEB-APPLICATION LINKS

\begin{tabular}{|l|c|c|c|}
\hline \multicolumn{1}{|c|}{ Categories } & $\begin{array}{c}\text { Web-application } \\
\text { link }\end{array}$ & No link & Total \\
\hline Auton. Comm. & 12 & 7 & 19 \\
\hline Provinces & 6 & 9 & 15 \\
\hline Cities & 19 & 13 & 32 \\
\hline Total & $\mathbf{3 7 ( 5 6 \% )}$ & $\mathbf{2 9 ( 4 4 \% )}$ & $\mathbf{6 6 ( 1 0 0 \% )}$ \\
\hline
\end{tabular}

Thirty-seven applications included a link from the webpage to the application download page, and in 34 of them the link was easy to identify in the home page.

Another important trait of the hypertextual architecture of a webpage or mobile application is the structure of links: an application may include links to external websites (centrifugal structure) or limit links to the application itself (centripetal structure) [22]. This category is important to detect how open to the network the application is. Even if a centrifugal (open) structure should be considered a positive feature of any website or application, in many cases the producers still prefer to keep the user 'imprisoned' in a centripetal (closed) environment.

In the specific case of Spanish tourism applications, $82 \%$ of them (54) bear links to external websites. In other words, the predominant link structure is centrifugal. 
TABLE VII

CENTRIPETAL-CENTRIFUGAL STRUCTURE

\begin{tabular}{|l|c|c|c|}
\hline \multicolumn{1}{|c|}{ Categories } & Centripetal & Centrifugal & Total \\
\hline Auton. Comm. & 5 & 14 & 19 \\
\hline Provinces & 2 & 13 & 15 \\
\hline Cities & 5 & 27 & 32 \\
\hline Total & $\mathbf{1 2 ( 1 8 \% )}$ & $\mathbf{5 4 ( 8 2 \% )}$ & $\mathbf{6 6 ( 1 0 0 \% )}$ \\
\hline
\end{tabular}

As we can see, most Spanish tourism applications present themselves as a centrifugal environment with connections to the rest of the web. Further research could explore the number and quality of these links on the context of network theory models [26].

\section{Applications and content}

It is not easy to classify mobile applications and content. Usually applications are considered tools for doing while content involves texts for knowing [21]. The explosion of new devices, applications and content seems to challenge both definitions. Should a tourism application with an audio-guide and an interactive map be considered as content or an application? And what about augmented reality? Is it content or an application? On this context: could the application be considered an interface that allows the user to consume content?

However, from the perspective of user experience, applications and content seem to be inextricably connected in the mobile environment. The field is so effervescent that any taxonomy proposed by the researcher must be constantly reviewed.

It is therefore not so easy to develop concepts, categories and classifications: the mobile market introduces new devices, applications and products every week, and any one of these could be a disruptive element in the mobile ecosystem. Even if the context is not stable, during the research the team classified the tourism applications taking into account the prevalence of one logic or the other (doing or knowing).

TABLE VIII.

APPLICATIONS FOR DOING - KNOWING

\begin{tabular}{|l|c|c|c|c|}
\hline \multicolumn{1}{|c|}{ Categories } & Doing & Knowing & Hybrid & Total \\
\hline Auton. Comm. & 4 & 4 & 11 & 19 \\
\hline Provinces & 4 & 3 & 8 & 15 \\
\hline Cities & 12 & 7 & 13 & 32 \\
\hline Total & $\begin{array}{c}\mathbf{2 0} \\
(\mathbf{3 0 . 5} \%)\end{array}$ & $\begin{array}{c}\mathbf{1 4} \\
(\mathbf{2 1} \%)\end{array}$ & $\begin{array}{c}\mathbf{3 2} \\
\mathbf{( 4 8 . 5 \% )}\end{array}$ & $\begin{array}{c}\mathbf{6 6} \\
(\mathbf{1 0 0} \%)\end{array}$ \\
\hline
\end{tabular}

If we take into account the genre of the applications, it would be interesting to note that 4 applications $(6 \%)$ were designed and produced as a mobile game: Visit Catalonia, Mission Euskadi, Tourkhana Segovia and Valladolid Aumentada.

\section{CONTENT}

This section the article focuses on the content of mobile applications. As stated above, all textual components (text, photographs, images, maps, sounds, videos, etc.) of the interface which convey information will be considered content. Aspects like origins, functions, identification and quality were evaluated by the research team.

\section{A. Origins}

Taking into account the origin of the content, it is possible to identify different application classifications: adapted, repurposed, original, augmented, etc. [21]. In the context of the research the team only focused on two variables: applications with original content and applications with contents adapted from other media (usually from the official tourism website). As shown in the following table, just over half of the applications (56\%) proposed original content:

TABLE IX

ADAPTED-ORIGINAL CONTENT

\begin{tabular}{|l|c|c|c|}
\hline \multicolumn{1}{|c|}{ Categories } & Adapted & Original & Total \\
\hline Auton. Comm. & 7 & 12 & 19 \\
\hline Provinces & 7 & 8 & 15 \\
\hline Cities & 15 & 17 & 32 \\
\hline Total & $\mathbf{2 9 ( 4 4 \% )}$ & $\mathbf{3 7 ( 5 6 \% )}$ & $\mathbf{6 6 ( 1 0 0 \% )}$ \\
\hline
\end{tabular}

\section{B. Functions}

Regarding the functions proposed by the mobile interfaces, the most important ones identified during the research were geolocation services, resources at the destination, agenda, augmented reality (AR), photo gallery and the possibility of sharing comments.

TABLE X.

FUNCTIONS

\begin{tabular}{|l|c|c|c|c|}
\hline Functions & $\begin{array}{l}\text { Autonomous } \\
\text { communities }\end{array}$ & Provinces & Cities & Total \\
\hline $\begin{array}{l}\text { Resources at the } \\
\text { destination }\end{array}$ & 16 & 14 & 24 & $\mathbf{5 4}(81 \%)$ \\
\hline Geolocation & 14 & 8 & 27 & $\mathbf{4 9}(\mathbf{7 4 \%})$ \\
\hline Agenda & 3 & 8 & 11 & $\mathbf{2 2}(33 \%)$ \\
\hline (AR) & 5 & 2 & 13 & $\mathbf{2 0}(\mathbf{3 0} \%)$ \\
\hline Photo gallery & 8 & 3 & 7 & $\mathbf{1 8 ( 2 7 \% )}$ \\
\hline Comments & 6 & 5 & 5 & $\mathbf{1 6}(\mathbf{2 4 \% )}$ \\
\hline Audio guide & 1 & 2 & 4 & $\mathbf{7 ( 1 0 \% )}$ \\
\hline Promotions & 0 & 1 & 3 & $\mathbf{4 ( 6 \% )}$ \\
\hline Place evaluation & 0 & 1 & 3 & $\mathbf{4 ( 6 \% )}$ \\
\hline Video guide & 1 & 0 & 1 & $\mathbf{2 ( 3 \% )}$ \\
\hline Other functions & 3 & 0 & 1 & $\mathbf{4 ( 6 \% )}$ \\
\hline
\end{tabular}

One of the most relevant findings is the high number of applications using latest generation technologies like geolocation (74\%) and augmented reality (30\%). If geolocation facilitates the identification of the real-world location of the mobile device (and its user), opening a still rather unexplored market for new services and specific content, augmented reality (AR) enhances the user perception of the environment in real time including new content like sound, video, graphics or GPS data. Even if AR was not very easy to check during the research - most of the AR systems only work in the actual place for which the application was designed to run - the high number of AR functions present in the Spanish market of tourism applications is particularly notable. Moreover, one of the easiest areas of content to produce - audio guides - is present on only 7 applications $(10 \%)$. The average number of functions is 3 . 


\section{Identification}

The research team also analyzed the quality of identification signs (naming and logotypes). In other words: can the user immediately identify where the application comes from? In $86 \%$ of cases the city, province or autonomous community was easy to recognize; $73 \%$ of applications included a logotype of the official institution or agency responsible for the promotion of the destination brand.

TABLE XI

IDENTIFICATION

\begin{tabular}{|l|c|c|}
\hline \multicolumn{1}{|c|}{ Categories } & Easy identification & Logo visible \\
\hline Auton.Comm. & 14 & 10 \\
\hline Provinces & 14 & 11 \\
\hline Cities & 29 & 27 \\
\hline Total & $\mathbf{5 7}(\mathbf{8 6 \% )}$ & $\mathbf{4 8 ( 7 3 \% )}$ \\
\hline
\end{tabular}

To conclude this first approach to the applications the team verified the updating of content: only 30 applications $(45 \%)$ had actually upgraded content during the week prior to the analysis.

\section{Content Quality}

After this first approach the team analyzed the quality of the different content and services included in the applications. The different information about location (maps), transport (buses, trains, airports, etc.), accommodation (hotels, campsites, etc.), visits (museums, monuments, etc.), agenda (exhibitions, cultural events, etc.), history and cultural issues (history of the place, cultural habits, etc.), and weather was evaluated according to three categories:

- No information

- Low quality information

- High quality information

We shall examine a couple of examples of how these categories were applied. For instance, the location (maps) was evaluated and positioned in one of the following categories:

- No information: the application did not include a map or the visualization of the map was not clear.

- Low quality information: the application included a map but it cannot be enlarged/reduced (zoom function) and/or it was not interactive.

- High quality information: the application included an interactive map.

In the specific case of history and cultural issues, the categories were understood in the following way:

- No information: the application did not include information about the history of the place or any other cultural issue.

- Low quality information: the application included incomplete and poorly organized information about the history of the place and cultural issues.

- High quality information: the application included complete information - photos, dates, etc. - about the history of the place and cultural issues.

To facilitate the visualization of the data in this table, we have unified the information from cities, provinces and autonomous communities.
TABLE XII.

INFORMATION

\begin{tabular}{|l|c|c|c|c|}
\hline \multicolumn{1}{c|}{$\begin{array}{c}\text { Content } \\
\text { Location }\end{array}$} & $\begin{array}{c}\text { No } \\
\text { info }\end{array}$ & $\begin{array}{c}\text { Low } \\
\text { quality }\end{array}$ & $\begin{array}{c}\text { High } \\
\text { quality }\end{array}$ & Total \\
\hline Transport & 7 & 4 & 55 & $\mathbf{6 6}(\mathbf{1 0 0 \% )}$ \\
\hline Accommodation & 26 & 24 & 7 & $\mathbf{6 6}(\mathbf{1 0 0 \% )}$ \\
\hline Visits & 22 & 32 & 12 & $\mathbf{6 6 ( 1 0 0 \% )}$ \\
\hline Agenda & 48 & 9 & 9 & $\mathbf{6 6 ( 1 0 0 \% )}$ \\
\hline History / cultural & 31 & 26 & 9 & $\mathbf{6 6 ( 1 0 0 \% )}$ \\
\hline Weather & 58 & 2 & 6 & $\mathbf{6 6}(100 \%)$ \\
\hline
\end{tabular}

As can be seen in the table, the Spanish tourism applications only showed a high quality score in the location (maps) category (55 applications - 83\%). In the other categories, from transport to weather, the quality of the content was very low or the content was not included in the applications. The data emerging from this comparative table does not speak highly about the content quality of the Spanish tourism applications. For example, it is shocking that 48 applications (73\%) do not include an agenda of the main cultural and economic events being held; the same may be said about weather information ( 58 applications: $88 \%$ do not include it).

\section{SOCIAL NETWORKS AND USER-GENERATED CONTENT}

The promotion and inclusion of user-generated content should be one of the main components of a transmedia branding strategy. This is especially true in the tourism sector [27]. In the last decade the explosion of social networks and sharing platforms has increased the production and distribution of content created by users. In this section we will present the results of research in the field of social networks and user-generated content. In certain applications (i.e., proBadajoz, BCN Cultural) the email function was considered a 'social network' as it was the only option for sharing content among users. These kinds of 'fake social networks' (emails, SMS, etc.) were included in the last category (Others: 43\%). Only one application (Región de Murcia) included a large series of social media (Delicious, GReader, Instapaper, Pinboard, and Tumblr).

TABLE XIII.

SOCIAL NETWORKS

\begin{tabular}{|l|c|c|c|c|}
\hline \multicolumn{1}{|c|}{ Network } & Auton. Comm. & Provinces & Cities & Total \\
\hline Facebook & 3 & 4 & 11 & $\mathbf{1 8 ( 2 7 \% )}$ \\
\hline Twitter & 3 & 4 & 7 & $\mathbf{1 4}(\mathbf{2 1 \% )}$ \\
\hline YouTube & 0 & 0 & 1 & $\mathbf{1}(\mathbf{0 . 1 5 \% )}$ \\
\hline Tripadvisor & 0 & 0 & 0 & $\mathbf{0}(\mathbf{0 \% )}$ \\
\hline Foursquare & 0 & 0 & 0 & $\mathbf{0 ( 0 \% )}$ \\
\hline Pinterest & 0 & 0 & 0 & $\mathbf{0}(\mathbf{0 \% )}$ \\
\hline Instagram & 0 & 0 & 0 & $\mathbf{0 ( 0 \% )}$ \\
\hline Flickr & 0 & 0 & 0 & $\mathbf{0 ( 0 \% )}$ \\
\hline Others & 9 & 10 & 10 & $\mathbf{2 9 ( 4 3 \% )}$ \\
\hline
\end{tabular}

Even if any 21 st century communication strategy must take into account the existence of social media - a kind of environment almost beyond the control of the official enunciators -, in the case of Spanish tourism applications dialogue with social networks is really low. Only $27 \%$ of the applications include a link to a Facebook page; the 
same may be said about Twitter: just 14 applications (21\%) include a link to a Twitter account.

The promotion and inclusion of user-generated content is one of the main components of contemporary transmedia strategies in fiction and non-fiction [28][29]. Tourism communication is not exempt from this concept: tourists generate huge amounts of content - from pictures to personal messages, hotel evaluations, restaurant recommendations, etc. - that any good communication strategy should take into account [9]. Are Spanish applications promoting the creation of 'tourist-generated content' [30]? Do they offer any online space for sharing such content? The answers to these questions are not very encouraging: only 15 applications (23\%) included a space for usergenerated content (comments) while only $9(14 \%)$ allowed users to upload pictures. In the following table we can see what kind of user-generated content they accepted:

TABLE XIV.

USER-GENERATED CONTENTS

\begin{tabular}{|l|c|c|c|c|}
\hline \multicolumn{1}{|c|}{ UGC } & Auton. Comm. & Provinces & Cities & Total \\
\hline Comments & 6 & 4 & 5 & $\mathbf{1 5}$ \\
\hline Photos & 5 & 1 & 4 & $\mathbf{9}$ \\
\hline Evaluations & 0 & 0 & 2 & $\mathbf{2}$ \\
\hline Links & 0 & 0 & 4 & $\mathbf{4}$ \\
\hline Videos & 0 & 0 & 1 & $\mathbf{1}$ \\
\hline
\end{tabular}

As can be seen, most Spanish tourism applications do not take into account the production of content by tourists. This component is still far removed from the dynamics of the mobile 2.0 philosophy, a field that is not precisely new in the media ecosystem [31][32].

\section{MODEL USERS}

As mentioned earlier, the research team complemented the quantitative description of the Spanish tourism applications - a method that showed the emerging traits of this mobile niche - with a semiotic analysis of them. If we consider interaction between humans and mobile devices as a semiotic process, research should focus on the interface - considered as a sense production device - and should analyze the ambiguous interplay between signification and interpretation played by designers and users. For semioticians this process is not a linear transmission of information (interface/user) but a cooperative one (designers/interface/user): both designers and users, mediated by the interface, participate in this contractual game of sense production. From this perspective, semiotics proposes qualitative research that complements traditional quantitative research [22]. In this specific case, the research team only developed a preliminary semiotic analysis of the applications, focusing on the concept of model user.

Like any text, the interface proposes a communication or exchange between subjects. From a semiotic perspective the interface may be considered the battlefield of two strategies: the designer's strategy and the user's strategy. To analyze this process the researcher should identify the designer's footprints, marks, and instructions inside the interface. This virtual figure or simulacrum of the designer inside the interface is called the enunciator or model (implied) designer. Furthermore, the interface 'is talking to' a specific user or category of users; this simulacrum of the user(s) is known as the enunciator or model (implied) user. This presence of virtual figures and exchanges is one of the bases of a semiotic approach to human-computer interaction [22][33].

Let us pick up on the question once more: who are Spanish tourism applications talking to? Who is the model user? We have already said that $60 \%$ of the applications were developed in only one language (usually Spanish). This first interpretation could be extended if we determine the profile of the model tourist constructed by the application. In this research the team identified three model tourists: the local tourist, the national tourist (Spanish) and the international tourist.

TABLE XV

MODEL USER (I)

\begin{tabular}{|l|c|c|c|c|}
\hline Model Tourist (I) & Auton.Comm. & Provinces & Cities & Total \\
\hline Local & 11 & 14 & 23 & $\mathbf{4 8}$ \\
\hline National & 19 & 15 & 32 & $\mathbf{6 6}$ \\
\hline International & 8 & 3 & 19 & $\mathbf{3 0}$ \\
\hline
\end{tabular}

As can be seen, all of the applications analyzed (66) addressed the Spanish tourist but only 30 (45\%) were directed to an international tourist. As for the local tourist, $72 \%$ of the applications (48) were addressed to them. In short, this table confirms that in general Spanish tourism applications do not address foreigners as they are focused on the national and local tourist. The city and autonomous community applications are those that are most oriented to international tourists (with 19 and 8 of them, respectively) while provinces privileged the local and national tourist.

Another important issue of the model tourist is given by the profile of the user. In other words: why is the tourist visiting the place? Leisure? Business? And what about the resident, that is, the subject who lives in the very place but likes to experience it as a tourist? From this perspective the team found the following situation:

TABLE XVI.

MODEL USER (II)

\begin{tabular}{|l|c|c|c|c|}
\hline Model Tourist (II) & Auton. Comm. & Provinces & Cities & Total \\
\hline Leisure & 19 & 15 & 32 & $\mathbf{6 6}$ \\
\hline $\begin{array}{l}\text { Business/ } \\
\text { Conference }\end{array}$ & 6 & 4 & 9 & $\mathbf{1 9}$ \\
\hline Resident & 9 & 10 & 16 & $\mathbf{3 5}$ \\
\hline
\end{tabular}

All of the applications were addressed to the traditional tourist who visits the place for leisure (66); however, only 19 applications (20\%) also addressed the business visitor. The low number of applications addressed to people coming for business or participating in a conference was remarkably reduced further (9) in the specific case of the city application. Finally, about half of the applications (35) were also addressed to local tourists. As we can see, most of the applications are not addressing international visitors and business travelers: they mostly concentrate on national leisure tourists.

\section{SPECIFIC CASES}

This section records some specific cases that emerged during the analysis. The first group relates to a collection of Spanish cities and autonomous communities that adopted the Minube platform for the creation of the applications (http://www.minubeapp.com/). Minube is a private online community devoted specifically to travel and tourism. It 
allows users to get inspired, and to plan and share their trips. They have also launched a mobile platform that allows destinations to create their own application. Even if the user can customize the interface, in most cases the final output is very similar. In Spain, city applications like Barcelona, Valencia and Tarragona, and community applications like Cantabria, La Rioja and Navarra have been produced using this platform. Even if the use of this platform facilitates and accelerates the production of the applications, the standardization of the interface limits the distinction between cities. If branding - in this case 'city branding' - is based on a clear distinction from your competitors, the creation of a standard application interface may homogenize the interactive environment and reduce its distinctive traits.

The second category of special cases is composed of some applications that did not even meet the minimum content that a professional product should deliver to users. During the research the team identified applications without photographs or maps. Applications like Albacete, ArabaMovil and Valladolid en tu corazón should be included in this list of low-level tourism applications. These applications demonstrate a low interest in developing a quality, useful digital product. In many cases, the applications are produced merely to join the bandwagon of mobile communication and not to offer the client excellent services and content. However, as we will show in the next paragraph, the panorama of Spanish tourism mobile applications also includes high-quality products.

Lastly, the third group has to do with some high quality applications identified in the research: Destino Región de Murcia, Córdoba, Gironain, Logroño.es, and others such as Tourkhana Segovia and Valladolid Aumentada. This last application proposes augmented reality technology in a recreational environment designed for the children of the tourists. A special mention should be given to the applications developed by Barcelona City Council. This institution offers a high number of applications and specific content about the city, for example there is an application devoted solely to city beaches (iBeach), another dedicated to local cultural events (CulturalBCN) and one for the development of the urban landscape ( $B C N$ Visual). Even though they are not similar, these applications lay out a roadmap for the future development of tourism applications: more services, more content, more specificity.

\section{CONCLUSIONS AND FUTURE WORK}

In this last section we resume the most important traits and trends emerging from the Spanish market of tourism mobile applications, as detected during the research:

- As in any other area, the emergence of mobile media is introducing new challenges to tourism communication and branding.

- In general, Spanish tourism applications are free-ofcharge, developed by public agencies and only in the Spanish language. Even if the presence of international tourists is strategic for the Spanish economy, the applications are still talking to the local user.

- The hypertextual structure of the applications is largely centrifugal (they include many links to the web) but only half of them have links to the official tourism website. Further research should explore whether this technological disconnect also implies a communicative disconnect. In other words: are online and mobile communication strategies integrated or are they independent?

- Many Spanish applications have introduced latest generation technology such as augmented reality and geolocation but the lack of quality in traditional content is alarming. In many cases applications do not include basic content or services like an agenda or weather information.

- Most Spanish tourism applications do not take into account the production of content by the tourist: they opt for a model based on the transmission of information. Moreover, half of the applications do not upgrade their content, an aspect which is fundamental to an optimal communication practice. The inclusion of user-generated content may be a cheap solution to that handicap: if institutions do not upgrade their content, why not let the user do it!

- When we applied semiotic categories such as the model user, we confirmed that Spanish tourism applications do not address foreigners. Most applications are only addressed to traditional tourists visiting the place for leisure; only a few of them take into account residents or people coming for business. In short, most Spanish tourism applications are not addressed to international visitors and business travelers.

\section{A. Towards a tourism application typology}

Towards the end of the research, the team took into account some features to identify the most frequent typologies of tourism applications in Spain. On this context the team established and analyzed the emergence of three distinct models:

- Content-based applications.

- Participatory applications.

- Leisure applications.

The content-based application frequently belongs to an urban destination and provides access to an average of three social networks. Usually it is an official application developed by an internal team and includes content in three different languages. These applications privilege knowing over doing and propose at least three functions. In most cases they do not include user-generated content and, even if there are some cases of freemium applications, they can be downloaded for free. Examples: $B C N$ Cultural, Valladolid en tu corazón, etc.

The participatory application frequently belongs to a regional destination and promotes the creation of usergenerated content. It is typical for these applications to be developed by an external producer; they have a single version in Spanish and are available in two operative systems. They usually belong to a hybrid category, that is, they mix doing and knowing. In many cases they can be downloaded for free, have an average of four functions and offer limited access to social networks. Some examples: Cantabria, La Rioja, Valencia, Navarra, etc.

The leisure application offers the user a game to learn or discover relevant features of the place being promoted. Hybridization with mobile games is evident in these applications. Examples: Visit Catalonia, Mission Euskadi, Tourkhana Segovia, Valladolid Aumentada, etc.

This research on mobile applications is just a part of a broader project about the institutional communication of 
Spanish tourist destinations. Future analyses will include other aspects like the relationships between online and mobile strategies or the consistency between mobile, online and traditional communication.

\section{REFERENCES}

[1] D. Buhalis \& R. Law, "Progress in Information Technology and Tourism Management: 20 years on and 10 years after Internet. The state of e-Tourism research", Tourism Management, 29 (4), pp. 609-623, 2008. http://dx.doi.org/10.1016/j.tourman.2008.01.005

[2] Y. Park, \& U. Gretzel, "Success factors for destination marketing web sites: a qualitative meta-analysis", Journal of Travel Research, 46, pp. 46-63, 2007. http://dx.doi.org/10.1177/00472 87507302381

[3] C. Blain, S.E. Levy \& J.R. Brent, "Destination branding: Insights and practices from destination management organizations", Journal of Travel Research, 43, pp. 328-338, 2005. http://dx.doi.org/10.1177/0047287505274646

[4] U., Gretzel, D. Fesenmaier, S. Formica J. \& O’Leary, "Searching for the future: Challenges faced by destination marketing organizations", Journal of Travel Research, 45, pp. 116-126, 2006. http://dx.doi.org/10.1177/0047287506291598

[5] N. Morgan \& A. Pritchard, Advertising in Tourism and Leisure, Oxford: Butterworth Heinemann, 2000.

[6] X: Li, \& Y. Wang, "Evaluating the effectiveness of destination marketing organisations' websites: Evidence from China", International Journal of Tourism Research, 12: 536-549, 2010.

[7] C. Luna-Nevarez \& M. Hyman, M., "Common practices in destination website design", Journal of Destination Marketing \& Management, 1, pp. 94-106, 2012. http://dx.doi.org/10.1016/j.jdmm. 2012.08.002

[8] Z. Xiang \& U. Gretzel, "Role of Social Media in Online Travel Information Search", Tourism Management, 31: 179-188, 2010. http://dx.doi.org/10.1016/j.tourman.2009.02.016

[9] Y. Lim, Y. Chung \& P.A. Weaver, "The impact of social media on destination branding: Consumer-generated videos versus destination marketer-generated videos", Journal of Vacation Marketing, 18 (3), pp. 197-206, 2012. http://dx.doi.org/10.1177/1356 766712449366

[10] M.Y. Hyun, S. Lee, \& C. Hu, "Mobile-mediated virtual experience in tourism: concept, typology and applications". Journal of Vacation Marketing, 15 (2), pp. 149-164, 2009. http://dx.doi.org/10.1177/1356766708100904

[11] D. Wang, S. Park, \& D.R. Fesenmaier, "The role of Smartphones in mediating the touristic experience", Journal of Travel Research, 51 (4), pp. 371-387, 2012. http://dx.doi.org/10.1177/00472 $\underline{87511426341}$

[12] V. Shankar \& S. Balasubramanian, "Mobile Marketing: A Synthesis and Prognosis", Journal of Interactive Marketing 23, pp. 118129, 2009. http://dx.doi.org/10.1016/j.intmar.2009.02.002

[13] S. Alqatan, D. Singh \& K. Ahmad, "A Theoretic Discussion of Tourism M-commerce", Journal of Convergence Information Technology, 6 (12), pp. 100-106, 2011. http://dx.doi.org/10.4156/ jcit.vol6.issue 12.13

[14] A. Alacovska, “'Parachute Artists' or 'Tourists With Typewriters': Creative and Cocreative Labor in Travel Guidebook Production", Communication, Culture \& Critique 6(1), p. 60, 2013. http://dx.doi.org/10.1111/cccr.12004

[15] J.K. Ayeh, N. Au, \& R. Law, "Predicting the intention to use consumer-generated media for travel planning". Tourism Management 35, pp. 132-143, 2013. http://dx.doi.org/10.1016/ j.tourman.2012.06.010

[16] L. Jeffres \& C. Lin, "Metropolitan Websites as Urban Communication", Journal of Computer-Mediated Communication, 11(4), pp. 957-980, 2006. http://dx.doi.org/10.1111/j.10836101.2006.00303.x

[17] U. Bastida \& T.C. Huan, "Performance evaluation of tourism websites' information quality of four global destination brands: Beijing, Hong Kong, Shanghai, and Taipei”. Journal of Business Research, November 2012. DOI: 10.1016/j.jbusres.2012.10.008.

[18] S. Karanasios, S. Burgess, \& C. Sellitto, "A Classification of Mobile Tourism Application"s. In Ordóñez, Tennyson and Zhao (eds.). Global Hospitality and Tourism Management Technologies, Hershey, PA: IGI Global, 2012, pp. 165-177. http://dx.doi.org/10.1016/j.jbusres.2012.10.008

[19] J. Fernández-Cavia \& M. López, "Communication, destination brands and mobile applications", Communication \& Society, 26 (2), pp. 95-113, 2013.

[20] C.A. Scolari, H. Navarro, I. García, H. Pardo Kuklinski \& J. Soriano, "The Barcelona Mobile Cluster:Actors, Contents and Trends", International Journal of Interactive Mobile Technologies 3 (3), pp. 47-54, 2009. URL: http://online-journals.org/ijim/article/view/814 http://dx.doi.org/10.3991/ijim.v3i3.814

[21] C.A. Scolari, J.M. Aguado \& C. Feijóo, "Mobile Media: Towards a Definition and Taxonomy of Contents and Applications", International Journal of Interactive Mobile Technologies, 6 (2), pp. 2938, 2012. http://dx.doi.org/10.3991/ijim.v6i2.1880

[22] C.A. Scolari, "The sense of the interface: applying Semiotics to HCI research", Semiotica, 177 pp. 1-27, 2009. http://dx.doi.org/10.1515/semi.2009.067

[23] J. Fernández-Cavia \& A. Huertas-Roig, "City Brands and their Communication through Web Sites: Identification of Problems and Proposals for Improvement", in Information Communication Technologies and City Marketing: Digital Opportunities for Cities around the World, Hershey, Pennsylvania: Information Science Reference, 2009, pp. 26:49.

[24] C. Rovira, J. Fernández-Cavia, R. Pedraza Jiménez, \& A. Huertas, "Posicionamiento en buscadores de las webs oficiales de capitales de provincia españolas", El Profesional de la Información 19(3), 2010. http://dx.doi.org/10.3145/epi.2010.may.08

[25] A. Huertas, C. Rovira \& J. Fernández-Cavia, "Interactivity as a key factor in city website visibility and place brand communication", Journal of Town \& City Management, 2 (2), pp. 132-142, 2011.

[26] B. Huberman, The Laws of the Web: Patterns in the Ecology of Information, Cambridge (MA): The MIT Press, 2001.

[27] D. Leung, R. Law, H. Hoof \& D. Buhalis, "Social Media in Tourism and Hospitality: a Literature Review", Journal of Travel \& Tourism Marketing, 30, pp. 3-22, 2013. http://dx.doi.org/10.1080/ $\underline{10548408.2013 .750919}$

[28] H. Jenkins, Convergence Culture. Where Old and New Media Collide. New York: NYU Press, 2006.

[29] C.A. Scolari, Narrativas transmedia. Cuando todos los medios cuentan. Barcelona: Deusto, 2013.

[30] A. M. Munar, "Tourist-created content: rethinking destination branding", International Journal of Culture, Tourism and Hospitality Research, 5 (3), pp. 291-305, 2011 http://dx.doi.org/10.1108/17506181111156989

[31] A. Jaokar \& T. Fish, T, Mobile Web 2.0.The innovator's guide to developing and marketing next generation wireless/mobile applications. London: FutureText, 2006.

[32] H. Pardo Kuklinski, J. Brandt \& J.P. Puerta, "Mobile Web 2.0. Theoretical-technical framework and developing trends", International Journal of Interactive Mobile Technologies 2(4), pp. 54-61, 2008. URL: http://online-journals.org/i$\mathrm{jim} /$ article/view $/ 535$

[33] C.A. Scolari, "Online brands: Branding, possible worlds, and interactive grammars", Semiotica 169-1/4, pp. 169-188, 2004. http://dx.doi.org/10.1515/SEM.2008.030

\section{AUTHORS}

Carlos A. Scolari is professor at the Department of Communication, Universitat Pompeu Fabra, Barcelona, Spain (e-mail: carlosalberto.scolari@upf.edu).

José Fernández-Cavia is professor at the Department of Communication, Universitat Pompeu Fabra, Barcelona, Spain (e-mail: jose.fernandez@upf.edu).

This research work has been funded by the project "Online Communication for Destination Brands. Development of an Integrated Assessment Tool: Websites, Mobile Applications and Social Media (CODETUR)" (CSO 2011-22691), of the Ministry of Economy and Competitiveness of the Spanish Government. More information at http://www.marca sturisticas.org (only in Spanish). Submitted 17 Februar, 2014. Published as re-submitted by the authors 05 April 2014. 